\title{
Health Economics II: Some Unique Aspects of Health Economics
}

This is the second article of a two-part Continuing Education series on economic principles that affect health care. This article describes how economic forces in the health care marketplace compare to those of other industries and some of the factors that influence supply, demand, and costs of health services. Knowledge of these basic economic principles will help pharmacists working in managed care environments to understand and respond to the economic forces shaping the health care market today.

KEYWORDS: Economics, health care costs, health economics, competition

J Managed Care Pharm 2000: 173-78

\section{Author}

KENNETH W SCHAFERMEYER, Ph.D., is Associale Professor and Director of Graduate Studies, St. Louis College of Pharmacy, 4588 Parkview Place, St. Louis, MO 63110.

ACKNOWLEDGEMENT: The author wishes to thank Kenteth W. Kirk, Ph.D., of the St. Louis College of Pharmacy for assistance with this manuscript.

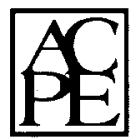

The Academy of Managed Care Pharmacy is approved by the American Council on Pharmaceutical Education as a provider of continuing pharmaceutical education. Individuals may obtain up to 1.0 contact hour of credit or .10 Continuing Education Units (CEUs). The ACPE number is 233-000-00-002-H04. Certificates will be mailed within six weeks to participants who successfully complete the $C E$ exam and achicve a score of $70 \%$ or more and submit the exam to AMCP prior to April 30, 2001. Learning objectives and test questions follow on page 180 .

Audience: Health care professionals interested in, or who practice in, managed care; those who want to increase their knowledge of managing and coordinating pharnaceutical care programs; and those responsible for optimizing patient care and satisjaction with managed care.

Copyright(0 2000 Academy of Managed Care Pharmacy, Inc. All rights reserved.

\section{by Kenneth W. Schafermeyer}

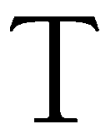
his is the second article of a two-part series designed to help pharmacists working in managed care environments to understand and respond to the economic forces shaping the health care market today. The first article, in the January/February 2000 issue of JMCP, presented the basic economic concepts of supply, demand, equilibrium price, the price system, price discrimination, and elasticity of demand. This second article will discuss some of the factors that influence supply and demand for health care services and how economic forces in the health care marketplace compare with those of other industries. In recent years we have seen renewed interest in reforming the health care system through the use of market forces rather than government regulations. One example of a market-based policy is the provision of subsidies to low-income patients for the purchase of health insurance rather than direct payments for health care services. Another example is the increased use of higher cost-sharing levels. 'The critical question, discussed in this paper, is whether the health care market fulfills the characteristics of a competitive market.

\section{Perfectly Competitive Industries}

To describe the unique aspects of the health care market, it is helpful to compare it with the four basic types of market structures: (1) perfect competition, (2) monopolistic competition, (3) monopoly, and (4) oligopoly. This article first describes a market structure known as perfect competition, then contrasts the perfectly competitive market with other types of market structures and discusses how the health care industry may or may not fall under one or more of these basic structures. Following are the criteria for a perfectly competitive industry:

Many buyers and many sellers. In perfect competition the number of buyers and sellers has to be large enough that the entry or exit of one firm or one customer into or out of the marketplace does not affect market prices. Companies in a perfectly competitive industry would not set prices; instead, the market would set prices. These firms are referred to as "price takers, not price makers." The demand curve for a company's product would be horizontal and referred to as "perfectly elastic." In other words, if a single company increased its price, customers would not demand (i.e., purchase) the product from the company that raised its price-they would just switch to another company.

Freedom of entry and exit. Most industries have barriers 
to entry or exit. Entry barriers can be patents, licenses, zoning, environmental regulations, or large investments in technology, training, inventories, or fixed assets, such as buildings, specialized equipment, or research and development. Exit barriers exist when a firm's fixed assets cannot be transferred to another use, thereby preventing a company from easily switching to a more profitable industry. Low barriers to entry into and exit from an industry stimulate competition; high barriers inhibit it.

Standardized product. In a perfectly competitive market, all products are similar and interchangeable and, therefore, there are many substitutes. Clothing, building materials, gasoline, tires, and many other products have standard sizes or grades, and substitutes can easily be identified by consumers.

Full and free information. Customers have complete information on prices of goods and services and can compare prices of competing sellers. Equally important, they can identify and compare the quality of these goods and services.

No collusion. Companies in a given industry must compete with each other rather than collude (get together to set prices). Collusion among sellers is more likely to be successful when sellers are few in number, know each other well, and are able to retaliate against each other if the agreement is broken. Because of its anticompetitive nature, collusion is illegal in the United States. Collusion does occur in international trade and the result is referred to as a cartel. The most famous cartel is the Organization of Petroleum Exporting Countries (OPEC).

Although no industry fits the perfectly competitive model exactly, agriculture is usually cited as being the industry closest. Although farmers can transfer their resources to producing different crops, they cannot usually do so in the short run. Also, products are fairly standardized, but there is still some differentiation by grade and by production method (e.g., organically grown or genetically engineered). Most industries, however, can be categorized into one of the other market structures.

\section{Other Market Structures}

The market structure closest to perfect competition is monopolistic competition. Despite its somewhat confusing name, monopolistic competition is similar to perfect competition except that it does not have standardized and interchangeable products. In most cases, firms in this industry rely heavily on product differentiation. These firms minimize price competition by differentiating their products from those of their competitors by promoting perceived or real advantages in style, image, quality, or other attributes (e.g., restaurants).

At the opposite extreme is a market structure known as a monopoly, which has only one seller of a product that has no close substitutes. To maximize income, monopolists do not have to produce as much output as possible; they can accomplish this same purpose by producing less and charging higher prices. Some monopolies are formed by controlling the supply source (e.g., DeBeers and the wholesale diamond market). Monopolies can also be created by barriers that prevent other firms from entering a market, such as legal restrictions (e.g., licenses, government approval, or patents). By granting patents, the government allows temporary monopolies to encourage research and innovation. Folland et al. claim that pharmaceutical firms that control patents for certain drugs without close substitutes may be considered to be monopolists during the life of the patent. ${ }^{2}$ With managed care formularies, however, competition can be created between some patented drugs and other therapeutic alternatives.

Other monopolies exist because the required infrastructure for the industry is so expensive that the presence of competing firms would increase, rather than decrease, prices. The primary examples of these natural monopolies are utilities. To ensure adequate output at reasonable prices, natural monopolies are usually regulated by government agencies such as public service commissions.

While a monopoly consists of only one seller, there are situations in which there is only one buyer. In this situation, known as a monopsony, it is the buyer who sets the price. The federal government is often a monopsony for military hardware and for health care services for Medicare and Medicaid patients. Unlike private businesses, however, the government is sometimes unable to fully exploit its market power to set prices because it is subject to political pressure and due process.

Between perfect competition and monopoly is a market structure known as oligopoly, which consists of few sellers and many buyers. Firms in oligopolies are often interdependent and a dominant firm can exert influence through price leadership. While this is short of collusion, pricing practices of the oligopolists tend to coincide with one firm taking a leadership role. Oligopolists know that the firms in the industry do not benefit if they all decrease prices. On the other hand, a single firm increasing its price may lose business if the other firms don't follow suit. This usually restricts the ability of smaller companies to change prices unilaterally. If a dominant firm, however, increases prices, others usually follow. Cereal manufacturers constitute a well-known oligopoly, as there are four major companies that have at least $80 \%$ of the market share for cereal. In medium-size urban areas, hospitals may represent an oligopoly. Certain drug classes with market share concentrated among a few manufacturers may also constitute an oligopoly.

\section{The Health Care Market}

Does the health care market fit the characteristics of any of the market structures described above? This remains a highly debated issue in economic circles. In a 1989 survey of health economists, half thought the competitive model could apply to the health care industry while the other half did not. ${ }^{3}$

Numbers of buyers and sellers. There is a maldistribution in the supply of health care services by geographic and specialty area. While some health care markets have large numbers of sellers (e.g., retail pharmacies), some communities have a shortage of health care providers or health care facilities. In addition, although the United States as a whole has a sufficient supply of physicians, there is a shortage of primary care physicians (and an oversupply of specialists). In some cases, the shortage exists because the market is just too small to support enough hospi- 
tals or providers in each specialty to create a competitive market (e.g., transplant services).

Furthermore, consolidation among buyers and sellers is occurring at a rapid pace. The numbers of sole practitioners and small group practices are shrinking while large medical groups are growing even larger. Likewise, health maintenance organizations, pharmacy benefit managers, pharmaceutical manufacturers, and drug wholesalers are merging into fewer, larger organizations. Employer groups have also pooled their purchasing power in many cities by forming employer health coalitions to negotiate better rates for health care services. Retail pharmacies have also participated in this trend: Chain pharmacies have consolidated and independent pharmacies have formed volume purchasing alliances and cooperatives. By consolidating, buyers and sellers find they can lower costs and have more market power to negotiate favorable prices. The concern is that too much consolidation could reduce competition. In some cases the Federal Trade Commission has intervened to restrict or prevent acquisitions and mergers that it felt would unduly inhibit competition.

Entry and exit from the market. There are high barriers to entry for suppliers of health care-both individual providers and institutions. To pursue a career as a health care provider, one must apply to a limited number of schools. Becoming a health care professional then can require significant education and compulsory licensure. These entry barriers effectively limit the number of new health care professionals that can be added to the labor force at any one time. Health care facilities must also be licensed, certified, and inspected and often require large capital investments. Of course, pharmaceutical manufacturers face extremely large financial barriers to getting new drugs approved by the Food and Drug Administration. These same barriers, however, can also inhibit potential competitors. Since health care resources are not easily transferred to producing other products and services, exit barriers are also quite formidable. For example, closing a hospital is difficult in part because it is not always possible to convert the building and equipment to other uses.

Variation in products, services and quality. Instead of producing standardized products and services, health care is usually customized for individual patients. There are also welldocumented variations in patterns of medical care. Quality, although hard to measure, also varies. For all these reasons, it can be difficult to identify true substitutes for a particular product or service.

Full and free information. Most health care services require specialized knowledge. Furthermore, although patients have more sources of information available today than ever before, they often have incomplete information about the prices and quality of health care services. Patients and other health care purchasers often do not know what constitutes good physician care or pharmaceutical care and cannot often tell when they are getting accurate information.

Inelastic demand. In perfect competition, small price increases result in significant loss of quantity demanded and, therefore, losses in revenue (i.e., demand is relacively elastic). Health care services, however, have an inelastic demandpatients who need health care services are usually not price sensitive, especially in emergency situations. In part because of this price insensitivity, prices for health care services grow more rapidly than those for most consumer goods and services. According to the Bureau of Labor Statistics, the Consumer Price Index for Urban Consumers (CPI-U) for medical care has increased during the past decade at twice the rate as it has for all items (65.5\% versus 33.9\%). Demand has also increased. For example, per capita prescription utilization has increased from 5.8 prescriptions per person per year in 1.992 to 8.3 in $1996.4,5$

As should be evident from the above discussion, many aspects of the health care industry do not fit the competitive model. In addition to the points described above, there are several other factors that make the health care market unique.

Universal demand. Many products and services offered for sale in the U.S. are used by only part of the potential market (e.g., rollerblades, cordless power tools, and high-adventure vacations). Health care products and services, on the other hand, are used by nearly everyone. Not only is demand universal, it is nearly insatiable. Because of the lack of complete knowledge, many people demand health care services that are of questionable value. Even those services that are usually helpful are sometimes used in inappropriate ways that produce little or no value (e.g., antibiotics for the common cold or heroic efforts to prolong life of a patient in the last stages of a terminal illness). In some cases, too many services may produce net losses (e.g., antibiotic resistance, addiction, iatrogenic disease, or unnecessary pain and suffering).

Unpredictability of illness. Given a large enough group of people, we can predict with some certainty the number of individuals who will need trauma care in the emergency room during a given period of time. We cannot, however, predict which people will need this care. Since consumers are often unable to time their health care purchases, they are typically not in a negotiating position when they need services. An obvious implication is the need to pool risk through health insurance, especially if done so through a managed care organization that is in a position to negotiate discounts before services are actually needed.

Health care as a "right." Many view health care as a "right" because it is a prerequisite for people to become useful, productive members of society (much like public education). Those who espouse this viewpoint also feel that the allocation of scarce resources should not be determined by people's ability and willingness to pay, as is the case with most goods and services; instead, some level of health care should be provided to everyone. This position holds, therefore, that the price system should not be the sole factor in deciding who will receive health care products and services.

Supplier-induced demand (SID). Physicians are in the unique position of controlling both the supply of and demand for health care services. Although patients do not usually gain 
Health Economics II: Some Unique Aspects of Health Economics

TABLE 1 Incentives under Various Forms of Hospital Reimbursement

\begin{tabular}{l|c|c|c}
\hline & Number of Admissions & Length of Stay & Intensity of Services \\
\hline Discounted fee-for-service & $\Uparrow$ & $\Uparrow$ & $\Uparrow$ \\
\hline Per diem & $\uparrow$ & $\Uparrow$ & $\Downarrow$ \\
\hline Prospective (DRGs) & $\Uparrow$ & $\Downarrow$ & $\Downarrow$ \\
\hline Capitation & $\Downarrow$ & $\Downarrow$ & $\Downarrow$ \\
\hline
\end{tabular}

Note: DRG is diagnosis-related group.

financially from illness or injury, their physicians often do. As the patients' agent, physicians can create demand for their services and, at the same time, supply the services. This potential conflict of interest is an inherent element of health care under fee-for-service reimbursement and is hard to prevent completely. Many managed care organizations, however, have restricted physicians' abilities to create self-referrals for laboratory, radiology, and other health care services.

Part $\mathbf{l}$ of this series illustrated that an increase in supply of most goods and services will result in an increase in equilibrium quantity and a decrease in equilibrium price. This is not necessarily the case in health care. Studies conducted in 1959 and 1961 first illustrated the effect of what is now called supplier-induced demand (SID) by showing a very close correlation between the number of hospital beds per 1,000 people and rates of utilization, measured as hospital days per 1,000 people. ${ }^{6.7}$ This led to an observation known as Roemer's Law, which states that a "bed built is a bed filled." The effect of SID has also been demonstrated by increases in utilization that often accompany attempts to impose controls on physician fees. ${ }^{B}$ Other studies have shown that physicians' clinical decisions can be influenced by financial incentives. ${ }^{9,10}$ This may explain, in part, why increases in the supply of physicians over the past two decades have been accompanied by acceleration, rather than moderation, in the growth of health care costs. It should be kept in mind, however, that increases in the supply of health care services may be favorable if they allow more people to access care or lead to improvements in quality.

Third-party insurance and patient-induced demand. The availability of insurance creates a form of induced demand that is initiated by patients. As discussed in Part 1 of this series, when the price of a product or a service decreases, the quantity demanded tends to increase. By decreasing patients' out-ofpocket expenses, health insurance has encouraged patients to consume more health care services than they would if they were bearing the full cost of the product or service. ${ }^{11}$ One of the concerns with expanding Medicare coverage for outpatient prescription drugs is the potential for growth in prescription drug use because of induced demand. A potential solution is patient cost sharing, which, if structured properly, can reduce unnecessary utilization without decreasing the quality of care. ${ }^{12}$ Of course, not all induced demand is undesirable. In some cases, reducing financial barriers to health care may encourage patients to seek health care services earlier and avoid more expensive health care in the future, particularly for lowerincome and more severely ill persons.

\section{Improving Economic Performance of the Health Care System}

Because of health care's unique economic aspects, strategies that successfully reduce costs in most industries (e.g., promoting an increase in supply or an increase in competition) are not as effective in the health care industry. Some individuals and groups, however, believe that health care is more monopolistic than competitive and, consequently, advocate that health care services should be considered a public utility and regulated accordingly. Indeed, many industrialized nations already do this and regulate both providers' fees and manufacturers' prices for pharmaceuticals. Recognizing that health care is unique, many public policy leaders and payors for health care services advocate instead that the health care industry be managed in a way that allows market forces to work more effectively. Some of the more common approaches are described below.

First, there are many ways in which individuals responsible for health care purchases (both patients and their physician "purchasing agents") can be made aware of and sensitized to health care costs. For patients, examples include receiving itemized receipts showing actual costs paid by insurance and requiring higher cost sharing, especially through tiered copayments. Health care providers, on the other hand, are receiving more feedback about variations in the cost, quantity, and quality of health care services through performance reports and academic detailing.

Second, managed care organizations are structuring physician and hospital reimbursement to create incentives for reducing costs. Since costs are a function of price and quantity, both factors need to be considered. Price (i.e., cost per unit) increases are due to inflation and can be controlled to some extent through contracting and competitive bidding. Increased utilization, however, is a function of three separate components:

(1) Population effects: the number of patients and the mix of various demographic factors within the group (i.e., sex, age, socio-economic status, and other factors which affect utilization). For hospitals, this translates into the number of hospital admissions; for physicians it is the number of new patients; and for pharmacies the number of new prescriptions;

(2) Duration of treatment: how long the patient continues 
receiving treatment. For hospitals this would be length of stay; for physicians it is the episode of care; and for pharmacies it is the number of prescription refills;

(3) Intensity of services: the types and numbers of services provided. This includes the service mix (types of services), the quantity (per capita use), and the quality of services. It can usually be expected that health care providers, like everyone else, respond to incentives.

Using the information above, one could consider the incentives created by each of the various types of managed care reimbursement for hospital services. As shown in Table 1, discounted fee-for-service creates incentives to increase admissions (i.e., population), length of stay (i.e., duration), and intensity of services. Per diem payment (the most common form of managed care reimbursement for hospitals) creates incentives for hospitals to increase admissions and length of stay but to decrease the intensity of services. ${ }^{13}$ Prospective reimbursement, such as reimbursement based on diagnosis-related groups (DRGs), creates incentives to increase admissions but minimize length of stay and intensity of services. Capitation, on the other hand, creates incentives to minimize all three utilization measures.

Physicians and pharmacies paid under discounted fee-forservice systems have the same incentives to increase utilization as do hospitals. Per diems, however, are difficult to apply to outpatient care services. Prospective payment systems and capitation can also be applied for outpatient services in the form of case management (or disease state management). Like DRGs, prospective payment for outpatient services is based upon diagnosis, but the mechanism is known as ambulatory patient groups (APGs). Although these programs are still being developed, they are expected to work best for chronic conditions with a wide range of costs. Again, health care providers in the outpatient setting would have the same types of incentives as would hospitals under prospective (APG) and capitation reimbursement.

A third approach to improving the economic performance of the health care system is balancing the cost of health care services with value received. As described in Part I of this series, most consumers will make purchases only when the marginal value of those services meets or exceeds the marginal cost. This principle does not always apply, however, in the health care industry because the patient and the payer are usually different entities. To illustrate, assume that the quantity of medical services (M) provided to a patient is compared with the patient's resulting health status $(\mathrm{H})$ as shown in Figure 1. The curve in Figure 1 illustrates a variation of the Law of Diminishing Marginal Utility discussed in Part I-marginal increases in the number of resources consumed result in smaller marginal increases in utility. Note that providing initial medical care services causes health status to improve rapidly at first and then as more and more medical care is provided, health status increases more slowly. At some point we will reach the "llat of the curve" where additional health care expenditures produce very little incremental benefit. ${ }^{14}$ When patients are isolated from costs, however, they often demand additional services even though these services may provide limit-

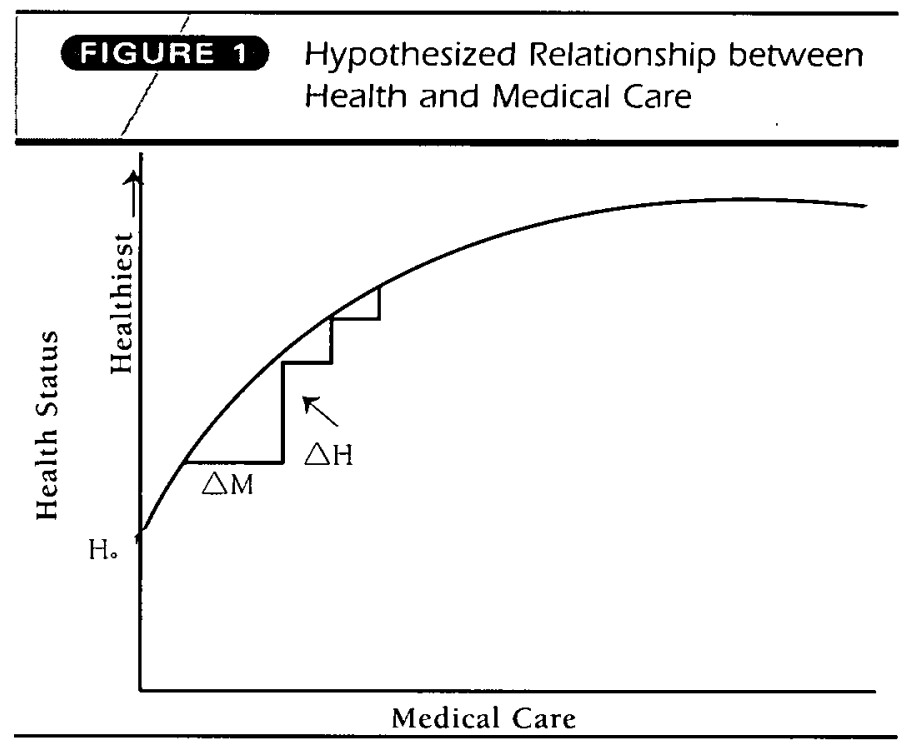

In this representation, additional doses of medical care have diminishing impacts on health; eventually, a situation of low medical productivity, termed "flat of the curve medicine," is reached. Source: Jacobs, P. The Economics of Health and Medical Care, 3rd Ed. Gaithersburg, MD: Aspen Publishers, Inc., 1991: 26.

ed or no benefits. What is important in our discussion here is to consider the marginal benefit of additional medical services and determine whether increases in services will produce proportional increases in benefits. If a great deal must be spent to produce a small incremental benefit, this may be a waste of limited health care resources.

This concept was employed by the state of Oregon when it faced a shortage of funds for its Medicaid program. Use of limited funds for some services meant that opportunities to help other patients had to be forgone. To minimize these opportunity costs, Oregon wanted to allocate resources in a manner that would maximize marginal outcomes. A decision was made to provide coverage for those treatments that provided the greatest benefits compared to the cost of services. By not covering procedures such as treatment of benign skin cancer, removal of benign tumors in the GI system, and liver transplants for liver cancer patients, the state was able to expand basic services to about 120,000 more uninsured patients. ${ }^{15}$

Although Oregon's experience has not been widely adopted, there are many other examples in which this principle is applied to some degree. Managed care organizations are giving more attention to pharmacoeconomic considerations (i.e., cost-effectiveness, cost benefit, and cost utility). Formulary decisions, step care protocols and disease management consider the incremental costs and outcomes of health care services. More attention will be given in the future to ways in which scarce health care resources can be applied more efficiently and effectively.

\section{Conclusions}

This article described some of the unique aspects of health eco- 
nomics and ways to enhance the economic performance of the health care system. Managed care pharmacists must understand and use these economic principles to effectively design and administer prescription drug programs. Because of the unique nature of the health care industry, payors are still learning ways in which they can control health care costs and improve quality so that patients can receive more benefits from the limited resources available.

\section{REFERENCES}

1. Rice T. Can markets give us the health system we want? J Health Polit Policy Law $1.997 ; 22(2)$ : 383-426.

2. Folland S, Goodman AC, Stano M. The economics of health and health care, 2d Ed. Upper Saddlc River, NJ: Prentice Hall, 1997: 47.

3. Feldman R, Morrisey MA. Health economics: a report on the field. J Health Polit Policy Law. 1990; 15 (3): 627-46.

4. Navarro RP. Novartis pharmacy benefit report: 1997 facts and figures. East Hanover, NJ: Novartis Pharmaceuticals Corporation, 1997): 12.

5. Marion Merrell Dow, Inc., Managed Care Digest, HMO Edition. Kansas City, MO: Marion Merrell Dow, 1994: 5.

6. Shain M, Roemer MI. Hospital costs relate to the supply of beds. Modern Hospital. 1959; $92: 71-73$.

7. Roemer MI. Bed supply and hospital utilization: a national experiment.
Hospitals, J Amer Hosp Assn. 1961; 35: 988-93.

8. Folland S, Goodman AC, Stano M. The economics of health and health care, 2d Ed. Upper Saddle River, N]: Prentice Hall, 1997: 169.

9. Hemenway D et al., Physicians' responses to financial incentives: evidence from a for-profit ambulatory center, N Eng J Med. 1990; 322: 1059-63.

10. Hillman AL, Pauly MV, Kerstein JJ. How do financial incentives affect physicians' clinical decisions and the financial performance of health maintenance organizations? N Eng J Med 1989; 321: 86-92.

1.1. Torrens PR, Williams SJ. Understanding the present, planning for the future: the dynamics of health care in the United States in the 1990s. In Williams SJ and Torrens PR, eds. Introduction to health services, 4th ed. Albany, NY: Delmar, 1993: 421-29.

12. Manning WG et al, Health insurance and the demand for medical care, Amer Economic Review 77 (1.987): 251.-77.

13. Kongstvedt PR, Negotiating and contracting with hospitals and institutions. Chapter 11 in Kongstvedt PR. Essentials of managed healch care, $2 \mathrm{~d}$ ed. Gaithersburg, MD: Aspen Publishers, 1997: 170.

14. Jacobs $P$, The economics of health and medical care, 3d ed. Gaithersburg, MD: Aspen Publishers, 1991: 25-26.

15. Clewer A, Perkins D, Economics for health care management. Hertfordshire, England: Prentice Hall Europe, 1998: 18. 
Upon completion of this article, the successful participant should be able to:

1. Compare and contrast the various types of market structures: perfect competition, monopolistic competition, oligopolies, and monopolies

2. Explain how the economics of health care is different from that of other industries.

3. Describe how the economic performance of the health care system could be improved.

4. Explain the factors that can cause health care costs to increase.

5. Describe how various forms of reimbursement can create different incentives to control utilization of health care.

\section{SELF-ASSESSMENT QUESTIONS}

1. A market structure that has a single buyer is known as a(n):
a. monopoly.
b. monopsony.
c. oligopoly.
d. monopolistic competition.
e. perfect competition.

2. Which of the following is a characteristic of a perfectly competitive industry?

a. Consolidation of buyers and sellers.

b. Licenses and patents that encourage firms to innovate.

c. Buyers are not price sensitive.

d. A firm's assets can easily be trans: ferred to production of other products or services.

e. Products and services are customized to fit the individual needs of customers.
3. Monopolistic competition differs from perfect competition in which of the following ways?

a. Monopolistic competition has few sellers with one dominant firm.

b. Patents and licenses prevent other firms from marketing close substitutes.

c. Competition is based on perceived or real differences in products rather than on price alone.

d. There are several suppliers but only one buyer.

4. Which of the following is a characteristic of the health care market?

a. High barriers to entry into and exit from the market.

b. Elastic demand.

c. Many buyers and sellers so that one party cannot affect the market alone.

d. Full and free information about costs and prices.

5. According to the article, consumers are not in a negotiating position when purchasing health care because of:

a. the universal demand for health care.

b. the unpredictability of illness.

c. the elastic demand of health care.

d. variation in quality of health care services.

e. supplier-induced demand.

6. Patient cost sharing is designed to minimize the effect of:

a. entry into and exit from the market.

b. full and free information.

c. elastic demand. d. patient-induced demand.

e. supplier-induced demand.

7. Utilization is a function of all of the following EXCEPT:
a. inflation
b. population
c. duration
d. intensity

8. According to the article, the most common form of managed care reimbursement for hospitals is:
a. fee-for-service.
b. discounted fee-for-service.
c. per diem.
d. diagnosis-related groups (DRGs).
e. capitation.

9. As the amount of medical care services increases:
a. health status increases more rapidly.
b. health status increases at a decreas- ing rate.
c. health status tends to stay the same.
d. health status decreases.

10. A type of prospective payment for outpatient services is known as:
a. discounted fee-for-service.
b. episode of care.
c. per diems.
d. diagnosis-related groups (DRGs).
e. ambulatory patient groups (APGs). 